\title{
Engineering the Catalytic Properties of HZSM5 by Cobalt Modification and Post-synthetic Hierarchical Porosity Development
}

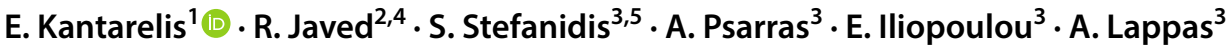

Published online: 22 May 2019

(c) The Author(s) 2019

\begin{abstract}
Hierarchical zeolites have been identified as special catalytic materials with improved catalytic properties. In this study, hierarchical bifunctional ZSM5 based catalysts were prepared by desilication for controlled mesoporosity development and have been modified by Co doping. Their performance in the catalytic pyrolysis of oak in a lab scale reactor was evaluated. Desilicated counterparts were proven more active in deoxygenation of bio oil, while carbon deposition on the catalysts reduced compared to non-desilicated counterparts. Increased Lewis acidity favors decarboxylation reactions, while higher olefins as well as PAH content indicate easier diffusion within and from the porous network and interactions in the mesopores. The conversion of bulky lignin molecules (alkoxy phenols) is enhanced by the mesopores, while acidity is of secondary importance. Coke deposition inside the pores is more profound in the desilicated catalysts due to larger pore size. Carbon deposition on the catalysts is reduced in the following order: HZSM5 > Co/HZSM5 > Ds-HZSM5 > Co/Ds-HZSM5. GC-MS characterization of the $\mathrm{CH}_{2} \mathrm{Cl}_{2}$ soluble coke indicated that for the desilicated counterparts the main coke precursors are the bulky lignin molecules which are partially deoxygenated.
\end{abstract}

Keywords Catalytic pyrolysis $\cdot$ Bio-oil upgrading $\cdot$ Catalytic cracking $\cdot$ Hierarchical zeolites

\section{Introduction}

The development of a sustainable society prioritises the use of renewable energy sources. Biomass is the main source of renewable carbon that can produce various valuable energy carriers providing one possible pathway for reshaping the present fossil based energy usage [1].

\section{E. Kantarelis}

ekan@kth.se

1 Department of Chemical Engineering, KTH-Royal Institute of Technology, Teknikringen 42, 10044 Stockholm, Sweden

2 Department of Mechanical Engineering, Eindhoven University of Technology, P.O. Box 513, 5600 MB Eindhoven, Netherlands

3 Laboratory of Environmental Fuels and Hydrocarbons, Chemical Process \& Energy Resources Institute (CPERI), 6th km Harilaou-Thermis, 57001 Thermi, Thessaloniki, Greece

4 Present Address: Department of Chemical Engineering, Wah Engineering College, Wah Cantt., Pakistan

5 Present Address: European Bioenergy Research Institute (EBRI), Aston University, Birmingham, UK
Biomass pyrolysis refers to its thermal decomposition in the absence of oxygen and is a process that could convert solid biomass mainly into liquid products. The process is reported for several years but it is only the last 20 years that has attracted considerable attention [2]. The derived liquid product of pyrolysis consists of several hundreds of compounds which are reactive, thermally liable and have a low heating value [3]. High water and oxygen content are related to undesired properties such as corrosiveness, chemical and thermal instability, high viscosity and incompatibility with conventional fossil based fuels [4]. Hence, upgrading of derived liquids is necessary.

One of the most promising ways for upgrading the derived liquids is to use heterogeneous catalysts integrated into the fast pyrolysis process [2]. Development of such process will offer a liquid of adequate quality for use in existing infrastructure. Highly selective catalysts for oxygen removal with maximum carbon preservation and minimum hydrogen scavenging is the key for successful development of the process.

Literature has indicated that microporous zeolites HZSM5 are the most promising materials for deoxygenation of pyrolysis vapors/liquids. Their hydrothermal stability, acid strength and density offer better performance compared 
to other types of zeolites (USY, beta etc.) [2]. However, their microporous structure affects the diffusion to and from the active sites and therefore the overall effectiveness of the catalyst.

The zeolite microenvironment plays an important role in defining the catalyst effectiveness, lifetime and product distribution [5]. Hierarchical zeolites have been identified as an important class of catalytic materials with improved catalytic properties and have been reported to outperform their microporous counterparts in a numerous of catalytic reactions [6]. Hierarchical zeolites offer an intrinsic acidity of microporous zeolites with reduced diffusional limitations, which is typical of mesoporous materials. The mesopores, due their size, provide improved access to the micropores thereby enhancing diffusion rate as well as the overall catalytic performance [7].

There is a wide variety of approaches for introduction of mesopores into microporous systems, such as synthesis of zeolites with larger pores, crystal size reduction, as well as introduction of a secondary porosity [8] and these methods can be categorized as "bottom-up" and "top-down" approaches $[6,8]$.

While "bottom-up" approaches include new synthetic routes with expensive templating compounds and harsh hydrothermal conditions, "top-down" approaches refer to post synthetic, cheaper and scalable modification techniques for introduction of mesoporosity $[6,8]$.

The effect of alkaline treatment has been demonstrated to increase the mesoporosity of the zeolite structure [9]. Desilication of ZSM-5 in alkaline solutions is a simple, efficient, reproducible, and scalable posttreatment to obtain combined micro- and mesoporous zeolites. The framework $\mathrm{Si} / \mathrm{Al}$ ratio of the MFI zeolite highly determines the proneness of the zeolite framework towards desilication, while $\mathrm{NaOH}$ has been found to be the most efficient medium to achieve substantial and controlled mesopore formation. The desilication treatment in $\mathrm{NaOH}$ is chemically controlled, allowing ease of scale-up. Several variables related to the material and the corresponding treatment conditions have been successfully identified and optimized $[9,10]$.

The hierarchical porosity could induce a more efficient usage of these materials in a variety of catalytic applications $[10,11]$. The combined intrinsic acidity and developed mesoporosity offer unique advantages for cracking of bulky molecules as those found in biomass. The cracking of large and branched molecules requires not only a tuned acidity but also an enhanced accessibility of the sites [10].

However, introduction of mesoporosity affects the acidic properties of the zeolites and therefore there is an optimum ratio between the mesopores and the micropores (assuming that most of the Brønsted acid sites are located in the micropores). The hierarchy factor (HF) is a good measure to quantify the extent of the mesoporosity development at the expense of micropore volume fraction (and thus Brønsted acidity), which simply put means how much micropore volume (and therefore acidity) is advantageous to sacrifice in order to produce mesoporosity while still improving the catalytic performance. The HF, is defined as the product of volume fraction of micropores $\left(\mathrm{V}_{\text {micro }} / \mathrm{V}_{\text {pore }}\right)$ and surface fraction of mesopores $\left(\mathrm{S}_{\text {meso }} / \mathrm{S}_{\mathrm{BET}}\right)$ [12, 13]: $H F=\left(\frac{V_{\text {micro }}}{V_{\text {pores }}}\right)\left(\frac{S_{\text {meso }}}{S_{\text {BET }}}\right)$. Desilication has been found to be the most versatile method of acidity-porosity alternation, showing a large number of zeolites in the both extreme ranges of $\mathrm{HF}(<0.1$ as well as $>0.2)$ [13].

Studies on desilicated ZSM5 zeolites have been conducted [14-16] providing insights of their activity yet variations in the desilication effects, bio oil quantity and quality are reported.

There is an enormous amount of studies in literature investigating Metal/HZSM-5 activity and selectivity of catalytic pyrolysis products. Studies on Co modified ZSM5 indicate that $\mathrm{Co}$ alters the acidic properties of the catalyst and affects the product selectivity favoring the formation of hydrocarbons while at the same time reduces the amount of produced coke [17-21]. To the best of the authors knowledge there is no work on Co modified hierarchical ZSM5 and the present work demonstrates the applicability of the Co modified hierarchical ZSM5 catalysts to the catalytic pyrolysis of biomass.

\section{Experimental Materials and Methods}

\subsection{Biomass Feedstock}

The biomass material used in the studied was oak wood with a particle size of $150-500 \mu \mathrm{m}$. The proximate and ultimate analyses of the material are listed in Table 1. Prior to use the biomass was dried at $105^{\circ} \mathrm{C}$ overnight.

\subsection{Catalyst Preparation}

The $\mathrm{Si} / \mathrm{Al}$ ratio is of crucial importance in the mesoporosity development, as framework aluminium proves to be the pore directing agent. A Si/Al range of $25-50$ for $\mathrm{Si}$ extraction was found optimal for well-controlled mesopore formation [22].

The parent zeolite was provided by Süd Chemie (TZP302) in $\mathrm{NH}_{4}^{+}$form $\left(\mathrm{NH}_{4}^{+}\right.$- ZSM5, molar $\left.\mathrm{Si} / \mathrm{Al}=28\right)$. Protonation of the untreated zeolite was carried out by calcination in air at $550{ }^{\circ} \mathrm{C}$ for $5 \mathrm{~h}$ at a heating rate of $2{ }^{\circ} \mathrm{C} / \mathrm{min}$. Incorporation of metal function (Co) was performed by means of incipient wetness impregnation; cobalt nitrate hexahydrate $\left(\mathrm{Co}\left(\mathrm{NO}_{3}\right)_{2} \cdot 6 \mathrm{H}_{2} \mathrm{O}\right)$ was used as metal precursor. The derived catalysts are designated as: HZSM5, Co/HZSM5 and respectively. 
Table 1 Proximate and ultimate analyses of biomass used

\begin{tabular}{|c|c|}
\hline \multicolumn{2}{|c|}{ Proximate analysis (wt $\%$ ) } \\
\hline Moisture & 10.00 \\
\hline Volatile matter & 82.00 \\
\hline Ash@ @550 ${ }^{\circ} \mathrm{C}$ & $<0.30$ \\
\hline $\mathrm{HHV}[\mathrm{MJ} / \mathrm{kg}]$ & 22.00 \\
\hline \multicolumn{2}{|c|}{ Ultimate analysis (wt\% db) } \\
\hline $\mathrm{C}$ & 49.5 \\
\hline $\mathrm{H}$ & 6.00 \\
\hline $\mathrm{N}$ & 0.19 \\
\hline $\mathrm{S}$ & 0.013 \\
\hline $\mathrm{Cl}$ & $<0.02$ \\
\hline $\mathrm{O}^{\mathrm{a}}$ & 44.10 \\
\hline \multicolumn{2}{|c|}{ Metals (mg/kg db) } \\
\hline $\mathrm{Si}$ & 36.7 \\
\hline $\mathrm{Al}$ & 13.1 \\
\hline $\mathrm{Ca}$ & 325 \\
\hline $\mathrm{Fe}$ & 12.3 \\
\hline $\mathrm{K}$ & 507 \\
\hline $\mathrm{Mg}$ & 40.2 \\
\hline Mn & 20.4 \\
\hline $\mathrm{Na}$ & 22.2 \\
\hline $\mathrm{P}$ & 20.7 \\
\hline $\mathrm{Ti}$ & 0.3 \\
\hline As & $<0.1$ \\
\hline $\mathrm{Ba}$ & 9.86 \\
\hline $\mathrm{Pb}$ & 0.164 \\
\hline $\mathrm{B}$ & 3.37 \\
\hline $\mathrm{Cd}$ & 0.0288 \\
\hline Co & 0.0267 \\
\hline $\mathrm{Cu}$ & 1.32 \\
\hline $\mathrm{Cr}$ & 0.107 \\
\hline $\mathrm{Hg}$ & $<0.02$ \\
\hline Mo & 0.00703 \\
\hline $\mathrm{Ni}$ & 0.19 \\
\hline $\mathrm{V}$ & $<0.01$ \\
\hline $\mathrm{Zn}$ & 0.502 \\
\hline
\end{tabular}

${ }^{a}$ Determined by difference

Desilication of the zeolite was carried out by treatment of the calcined zeolite (HZSM5) in a $\mathrm{NaOH}$ solution $(0.2 \mathrm{M}$, $100 \mathrm{ml}$ solution per $3 \mathrm{~g}$ of zeolite) at $65^{\circ} \mathrm{C}$ for $30 \mathrm{~min}$. After desilication, the zeolite was cooled in an ice bath, filtered, washed until neutral $\mathrm{pH}$ and dried overnight at $100{ }^{\circ} \mathrm{C}$.

Next, a fourfold ion-exchange with $0.1 \mathrm{M} \mathrm{NH}_{4} \mathrm{NO}_{3}(40 \mathrm{ml}$ per gram of zeolite) was performed at $60{ }^{\circ} \mathrm{C}$ for $1 \mathrm{~h}$. Finally, the zeolites were again filtered, washed and dried overnight. Calcination and metal incorporation were performed as previously described. The desilicated catalysts are designated as Ds-HZSM5, Co/Ds-HZSM5.
Prior to use the catalysts were pressed and crushed to a particle size of 90-180 $\mu \mathrm{m}$. The metal content of the resulted catalysts determined by ICP/OES and is shown in Table 2.

\subsection{Catalyst Characterization}

All the catalysts were characterized by means of $\mathrm{N}_{2}$ physisorption using a Micromeritics ASAP 2000 physisorption analyzer. Prior to analysis, each sample was calcined and then degassed at $250{ }^{\circ} \mathrm{C}$ overnight under vacuum. Isotherms were recorded at $77 \mathrm{~K}$, and the Brunauer-Emmett-Teller (BET) method was used to estimate surface area. The pore size distribution was determined using BJH method while the micropore volume was determined using the t-plot method.

X-ray powder diffraction (XRD) was used to determine the crystallinity and the metal phases present, using a Bruker D8 advance diffractometer using CuKa radiation $(\lambda=1.5408 \AA)$. The samples were finely ground in a mortar prior to the analysis and they were then loaded in a stainlesssteel sample holder. The apparatus is operated in reflection mode without the use of internal standard. The samples were scanned at a $2 \theta$ range of $5^{\circ}-75^{\circ}$ at a scan rate of $1.5^{\circ} / \mathrm{min}$ and a step size of $0.02^{\circ}$.

Additionally, temperature programmed reduction (TPR) of Co modified catalysts using a Micromeritics AutoChem 2910 was carried out in order to determine the Co state on the catalysts. Prior to reduction the samples were purged with helium at $110{ }^{\circ} \mathrm{C}$ for $1 \mathrm{~h}$ and subsequently were subjected to TPR at a temperature ramp rate of $5{ }^{\circ} \mathrm{C} / \mathrm{min}$ until a final temperature of $700{ }^{\circ} \mathrm{C} .5 \% \mathrm{H}_{2}$ in $\mathrm{Ar}$ was used as reducing gas.

Acidity of the catalysts was determined by means of FTIR spectroscopy with pyridine adsorption. The IR spectra were collected using a Nicolet 5700 FTIR spectrometer (resolution $4 \mathrm{~cm}^{-1}$ ) by means of OMNIC software. All the samples were finely ground in a mortar and pressed in selfsupporting wafers $\left(\sim 15 \mathrm{mg} / \mathrm{cm}^{2}\right)$. The wafers were placed in a custom-made stainless steel, vacuum cell, with $\mathrm{CaF}_{2}$ windows. High vacuum is reached by the means of a turbomolecular pump and a diaphragm pump placed in line. The infrared cell was equipped with a sample holder surrounded by a heating wire and a thermocouple for the heating steps and connected to the vacuum line, which is also heated in order to avoid pyridine condensation or its adsorption on the walls. Before IR analysis, all samples were heated at $450{ }^{\circ} \mathrm{C}$ under high vacuum $\left(10^{-6} \mathrm{mbar}\right)$ for $1 \mathrm{~h}$ in order to desorb any possible physisorbed species (activation step). All spectra were collected at $150{ }^{\circ} \mathrm{C}$ in order to eliminate the possibility of pyridine condensation. Initially, the reference spectrum of the so-called activated sample is collected. Then adsorption of pyridine is realized at 1 mbar by equilibrating the catalyst wafer with the probe vapours, added in pulses 
Table 2 Textural properties of catalysts

\begin{tabular}{lllclll}
\hline & $\mathrm{S}_{\mathrm{BET}}\left(\mathrm{m}^{2} / \mathrm{g}\right)$ & $\mathrm{S}_{\text {micro }}^{\mathrm{a}}\left(\mathrm{m}^{2} / \mathrm{g}\right)$ & $\mathrm{S}_{\text {external }}^{\mathrm{b}}\left(\mathrm{m}^{2} / \mathrm{g}\right)$ & $\begin{array}{l}\mathrm{V}_{\text {micro }}^{\mathrm{b}} \\
\left(\mathrm{cm}^{3} / \mathrm{g}\right.\end{array}$ & $\begin{array}{l}\mathrm{V}_{\text {pores }}^{\mathrm{c}} \\
\left(\mathrm{cm}^{3} / \mathrm{g}\right.\end{array}$ & $\begin{array}{l}\text { Metal } \\
\text { content } \\
(\mathrm{wt} \%)\end{array}$ \\
\hline HZSM5 & 384.8 & 293.5 & 91.3 & 0.117 & 0.237 & \\
Ds-HZSM5 & 405.7 & 285.2 & 120.5 & 0.115 & 0.253 & \\
Co/HZSM5 & 377.1 & 290.4 & 86.7 & 0.114 & 0.225 & 4.3 \\
Co/Ds-HZSM5 & 397.2 & 295.5 & 101.7 & 0.116 & 0.243 & 4.1 \\
\hline
\end{tabular}

${ }^{\mathrm{a}} \mathrm{S}_{\mathrm{BET}}-\mathrm{S}_{\text {external }}$

${ }^{b}$ t-plot method

${ }^{\mathrm{c}}$ Single point at $\mathrm{p} / \mathrm{p}_{0}=0.995$ for $1 \mathrm{~h}$. The desorption procedure of pyridine is stepwisely monitored by evacuating the sample for $30 \mathrm{~min}$ at 150,250 , 350 and $450{ }^{\circ} \mathrm{C}$ and cooling down to $150{ }^{\circ} \mathrm{C}$ after each step to record the corresponding spectrum.

Moreover, the parent (HZSM5) and desilicated (DsHZSM5) zeolites were characterized by means of TG-DSC, using a NETZCH Jupiter F3 TG/DSC analyzer, to assess the effect of alkaline treatment on the thermal stability of the zeolite.

\subsection{Catalytic Pyrolysis Experiments}

All the experiments were performed at CPERI-laboratory of Environmental Fuels and Hydrocarbons, Thessaloniki, Greece. Detailed description of the experimental facility and procedures can be found elsewhere [23, 24].

The experiments were performed at $500{ }^{\circ} \mathrm{C}$, with the catalyst bed temperature considered as the experiment temperature and was monitored by a thermocouple.

Prior to use, catalysts (or sand in the case of thermal run) were treated in static air for $2 \mathrm{~h}$ at $500{ }^{\circ} \mathrm{C}$.

Initially, the reactor was filled with $0.5 \mathrm{~g}$ catalyst or $0.7 \mathrm{~g}$ silica sand for the catalytic and non-catalytic tests, respectively, and the reactor was heated to reaction temperature. The biomass feeding piston was filled with $1.5 \mathrm{~g}$ of biomass. The experiment began (using a $100 \mathrm{~cm}^{3} / \mathrm{min}$ nitrogen flow) by introducing the biomass into the reactor that had previously reached the desired temperature. At the end of the experiment ( $15 \mathrm{~min}$ ), two of the three reactor heating zones were switched off and the reactor purged with $\mathrm{N}_{2}\left(50 \mathrm{~cm}^{3} /\right.$ min) while 10 min later all heating sources were switched off. A typical residence time of the vapor phase in the catalyst bed was $0.031 \mathrm{~s}$.

The liquid products were collected and quantitatively measured in the pre-weighted glass receiver. The gas products were collected and measured by the water displacement method and the amount of the solid residue was measured gravimetrically. The solid products consisted of char (biomass residue) and coke-on-catalyst formed by thermal and catalytic cracking, as well as a very small amount of unreacted biomass. Duplicates were performed to ensure repeatability and the corresponding average values as well as standard deviations are presented.

\subsection{Product Analyses}

As mentioned, the bio-oil was collected in a pre-weighted glass receiver. The pyrolytic vapors, upon their condensation in the receiver, formed multiple bio-oil phases; an aqueous phase, a liquid organic phase and viscous organic deposits on the receiver walls. After weighting the receiver to determine the bio-oil yield, a known quantity of ethyl lactate was introduced in the receiver and following manual mixing by shaking, the bio-oil was collected as a homogeneous solution. The water content of the bio-oil was determined by Karl Fisher titration, after accounting for the added ethyl lactate, while the elemental composition of the bio-oil's organic components was determined by analysis in a LECO CHN-800 elemental analyzer, after accounting for the added ethyl lactate and the bio-oil's water content.

After the determination of water content and elemental composition, dichloromethane was added to the bio-oil sample to separate the solution into an organic dichloromethane-soluble fraction and an aqueous fraction. The organic fraction was then analysed using an Agilent 7890A/5975C gas chromatograph-mass spectrometer system (Electron energy $70 \mathrm{eV}$; Emission $300 \mathrm{~V}$; Helium flow rate: $0.7 \mathrm{cc} /$ min; Column: HP-5MS $30 \mathrm{~m} \times 0.25 \mathrm{~mm}$ ID $\times 0.25 \mu \mathrm{m})$. Internal libraries (NIST 11) were used for the identification of the compounds found in the bio-oil. The amount of each product group was expressed as the percentage per gram of feed, calculated based on the product of the relative area $(\%)$ of each component determined by the GC-MS analysis, and the weight percentage of the organic fraction. By taking into account the amount of bio-oil fed, this approach enables the most accurate form of qualitative comparison [25, 26].

The gaseous products were analyzed in a HP 5890 Series II gas chromatograph, equipped with four columns 
(Precolumn: OV-101; Columns: Porapak N, Molecular Sieve $5 \mathrm{~A}$ and Rt-Qplot $(30 \mathrm{~m} \times 0.53 \mathrm{~mm}$ ID) and two detectors (TCD and FID). The chromatograph was standardized with gases at known concentrations as standard mixtures. Gas products consisted of $\mathrm{CO}, \mathrm{CO}_{2}, \mathrm{CH}_{4}, \mathrm{H}_{2}$ and hydrocarbons with up to six carbon atoms.

Coke was analysed according to procedure described by Magnoux et al. [27]. $100 \mathrm{mg}$ of catalyst were dissolved in $10 \mathrm{ml}$ of $40 \% \mathrm{HF}$ solution in order to liberate the coke. Coke extracted using $\mathrm{CH}_{2} \mathrm{Cl}_{2}(4 \mathrm{ml})$. The $\mathrm{CH}_{2} \mathrm{Cl}_{2}$ soluble coke was subsequently analysed by GC/MS.

The total carbon deposited on the catalysts was determined by elemental analysis using a LECO CHN-800 elemental analyzer.

\section{Results and Discussion}

\subsection{Catalyst Characterization}

The crystal structure of each material was confirmed by powder XRD. All the catalysts exhibit the characteristic MFI diffraction pattern (Fig. 1). The relative crystallinity of the Ds-HZSM5 was determined by integrating the intensity signal between the angles $2 \theta$ of $23^{\circ}-25^{\circ}$ [28] and equalled to $81.8 \%$.

Co impregnation resulted in further reduction in the relative crystallinity in both zeolites. The relative crystallinities equalled to $66.1 \%$ and $69.4 \%$ for the Co/HZSM5 and Co/ Ds-HZSM5 respectively.

Crystallite size of $\mathrm{Co}_{3} \mathrm{O}_{4}$ calculated using the Scherrer equation: $L=K \times \frac{\lambda}{B \cos \theta}$, where $\mathrm{L}$ is average crystal size (approximation), $\mathrm{K}$ is a constant equal to 0.89 and $\mathrm{B}$ is the

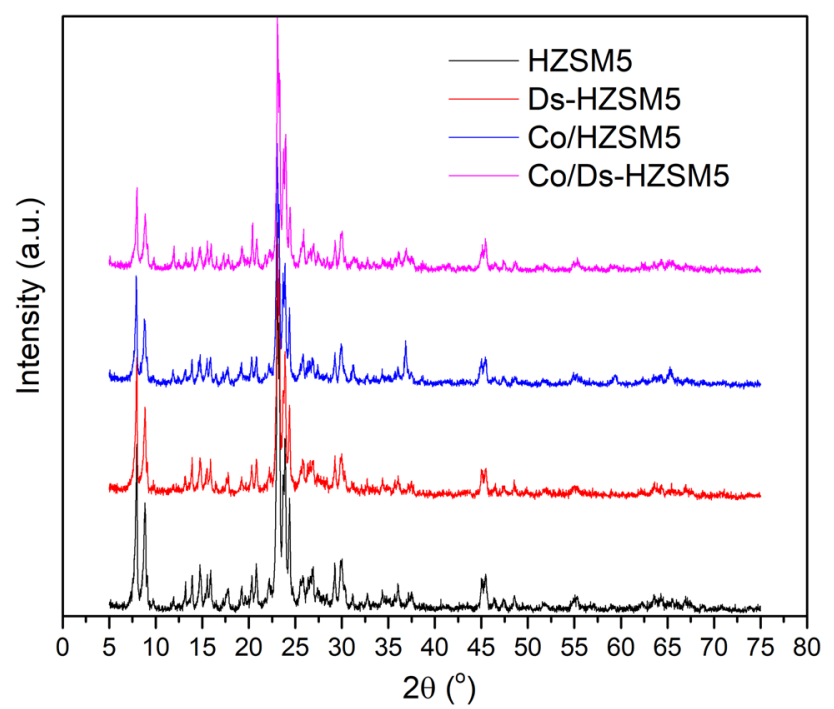

Fig. 1 XRD patterns of fresh catalysts used in catalytic pyrolysis tests full width at half maximum of the selected peak at $2 \theta$. The average Co crystallite sizes for the Co/HZSM5 and Co/DsHZSM5 were evaluated at $2 \theta=36.9^{\circ}$ (characteristic peak for $\mathrm{Co}_{3} \mathrm{O}_{4}$ ) were equal to 60.2 and $36.1 \mathrm{~nm}$ respectively. This indicates better dispersion of additional Co species. $\mathrm{H}_{2}$-TPR (Fig. 2) revealed the main reduction peaks at temperatures lower than $400{ }^{\circ} \mathrm{C}$ which are ascribed to the reduction of $\mathrm{Co}_{3} \mathrm{O}_{4}$ that proceeds via a multistep mechanism (reduction of $\mathrm{Co}_{3} \mathrm{O}_{4}$ to $\mathrm{CoO}$ and then to metallic $\mathrm{Co}$ ) $[29,30]$.

Alkaline treatment increased the total surface area by 5\% while the micropore area has been decreased. The total pore volume increased by $\sim 7 \%$ contrary to the micropore volume which has been decreased (Table 2). The pore size distribution for the catalysts is shown in Fig. 3. The main effect of the treatment resulted in increase of the pores in the range of 5-20 nm. Metal deposition resulted in reduced surface area and pore volume in both cases (parent and desilicated zeolite). The micropore volume has been preserved after metal modification indicating that Co is mainly deposited in the mesopore cavities. The HF after desilication has been increased from 0.12 to 0.14 indicating the development of mesoporosity. The molar $\mathrm{Si} / \mathrm{Al}$ ratio of the desilicated zeolite was equal to 24.7 which verifies the Si removal.

Figure 4 shows the $-\mathrm{OH}$ stretching region in the IR spectrum for parent and desilicated zeolites. The band at $\sim 3740 \mathrm{~cm}^{-1}$, which corresponds to terminal silanol groups, is more intense for the desilicated zeolite and indicates an increase of the ratio between the external/mesopore surface and the micropores' surface that lacks silanol groups [10, 31-33]; The $3720 \mathrm{~cm}^{-1}$ band which corresponds to hydroxyl nests vanishes after alkaline treatment. The band at approximately $3610 \mathrm{~cm}^{-1}$ is characteristic of Brønsted acid sites (bridged $\mathrm{Al}(\mathrm{OH}) \mathrm{Si}$ groups-framework $\mathrm{Al}$ ) and is

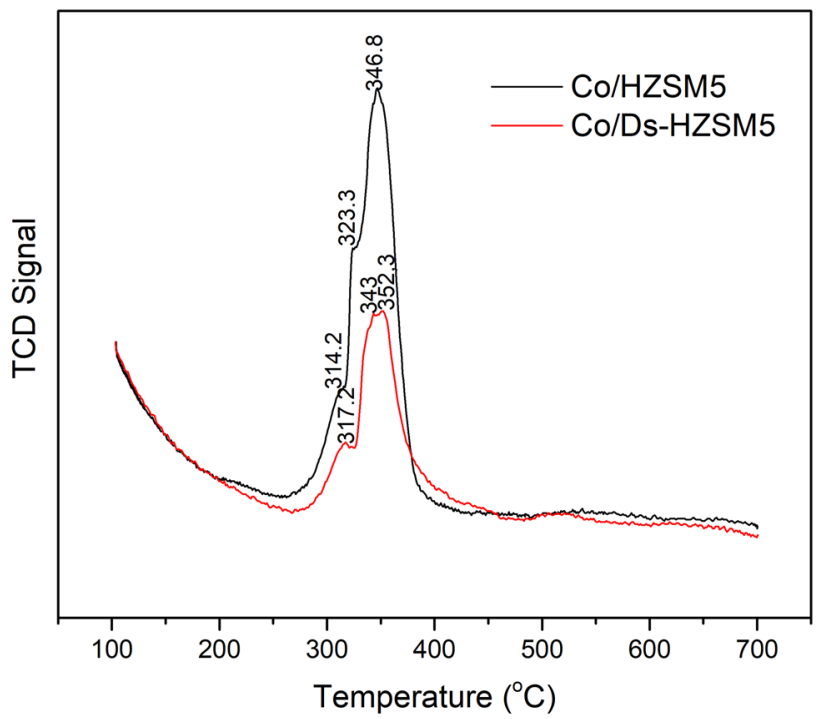

Fig. $2 \mathrm{H}_{2}$-TPR profiles of Co modified catalysts 

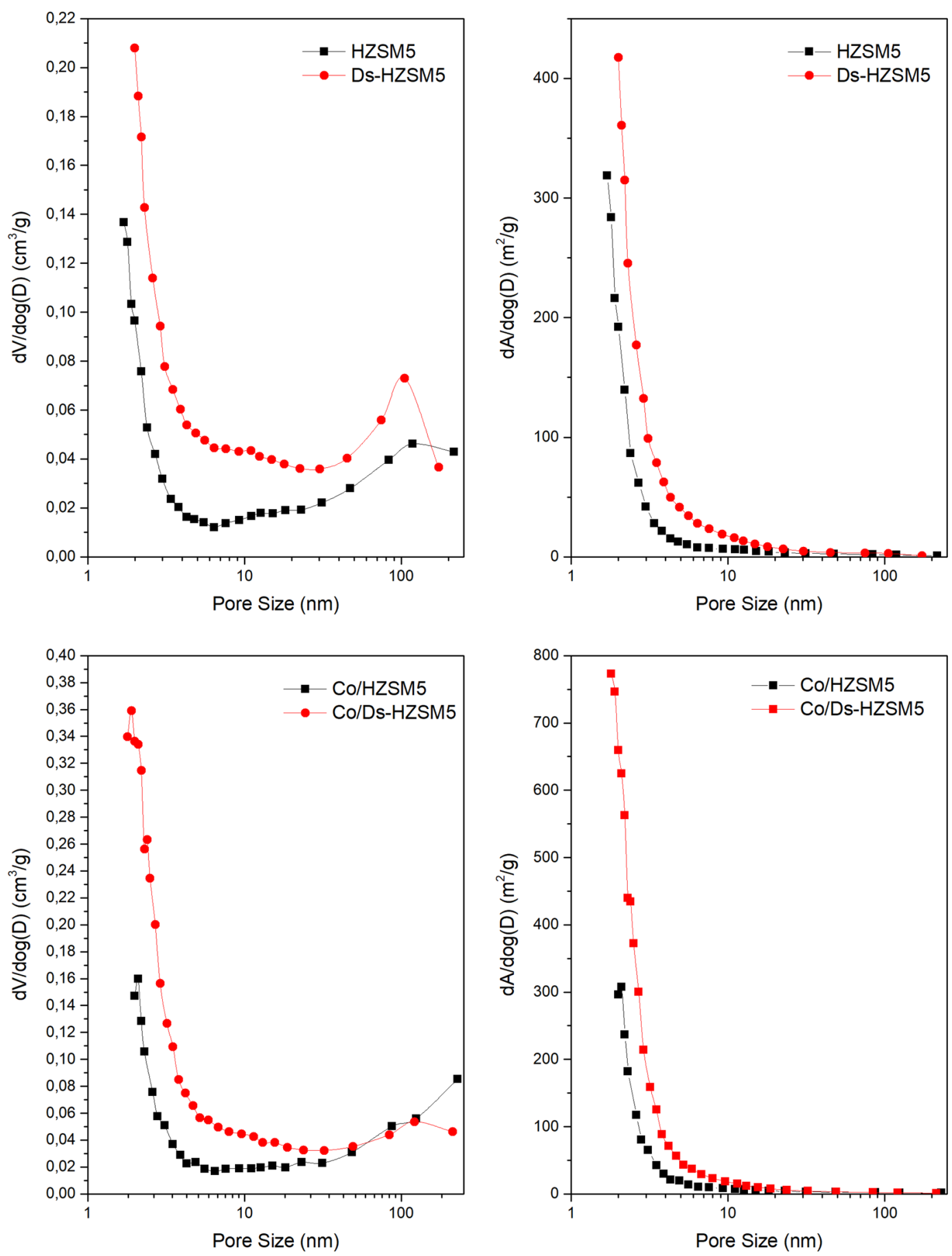

Fig. 3 Effect of desilication and Co impregnation on pore volume and pore area size distribution (BJH method)

preserved after treatment. The band at $3780 \mathrm{~cm}^{-1}$, which corresponds to hydroxyl groups connected to partially framework Al (not tetrahedral), is unchanged [34, 35].

Desilication resulted in decreased Brønsted acidity while slight increase in Lewis acid sites is observed with similar effects being reported elsewhere [36, 37]. It has been suggested that the transformation of some of the
Brønsted sites into Lewis sites is possible. This observation is in agreement with the recent spectroscopic studies on desilicated ZSM-5 [12,33] where extraction of some lattice $\mathrm{Al}$ to extra-framework positions during $\mathrm{NaOH}$ treatment was realized. As reported by Groen et al. [10], limited Al removal takes place during desilication however, the amount deposited as amorphous species is 


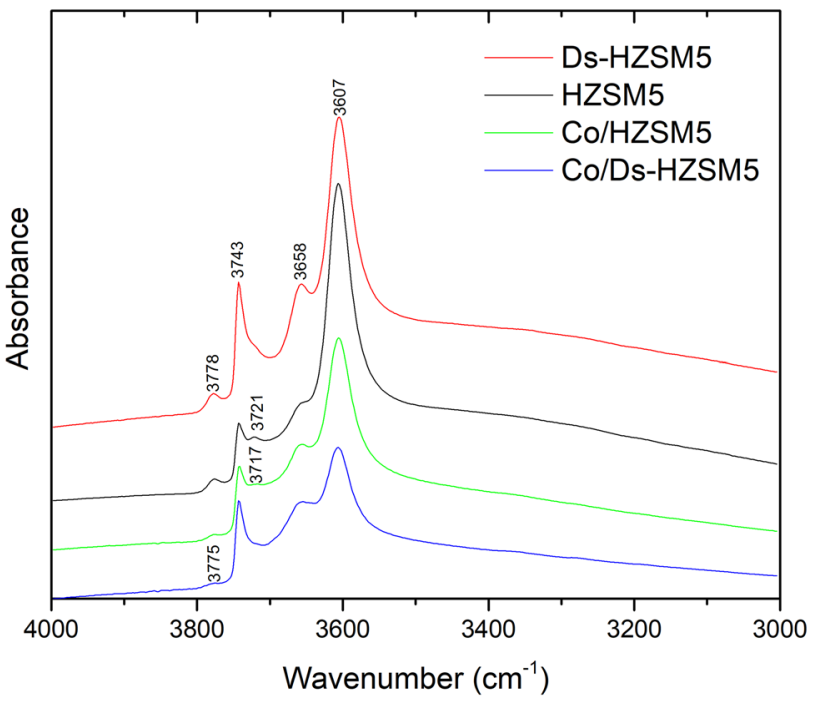

Fig. 4 FTIR spectra in the $-\mathrm{OH}$ stretching region of untreated, desilicated HZSM5 and corresponding Co modified counterparts

limited as shown by the small increase in the $\mathrm{Al}-\mathrm{OH}$ band at $3660 \mathrm{~cm}^{-1}$ resulting in Lewis acidity [37]. The creation of extra framework Al are also plausibly a result of air calcination at ambient pressure where desorption of water is slower and therefore, limited dealumination occurs [32]. The strength distribution of Brønsted sites is similar both for untreated and desilicated zeolite (Table 3).

Introduction of metal functions decreases the Brønsted sites, while it enhances remarkably the Lewis acid concentration. The decrease of Brønsted acid sites upon Co impregnation suggests that $\mathrm{Co}^{+2}$ exchanges some of the protons in the zeolite [38]. Decreased Brønsted acidity (band at $3607 \mathrm{~cm}^{-1}$ (Fig. 4; Table 3) of the Co/Ds-HZSM5 compared to Co/HZSM5 and Ds-HZSM5 suggests that, that the $\mathrm{Co}^{+2}$ ions are mainly located at the bridging oxygen of $\mathrm{Si}-\mathrm{OH}-\mathrm{Al}$ groups(assigned as $[\mathrm{CoOH}]+$ vibration) [39, 40]. Moreover, the disappearance of the external silanol groups $\left(\sim 3720 \mathrm{~cm}^{-1}\right)$ (Fig. 4) suggests that a small part of the impregnated Co species is located at the external zeolite surface. In contrast to the Brønsted acid sites, the number of Lewis acid sites was significantly increased, mainly due to the formation of the corresponding oxides, i.e. $\mathrm{Co}_{3} \mathrm{O}_{4}$ (Fig. 8) which could function as Lewis acidic centers [19].

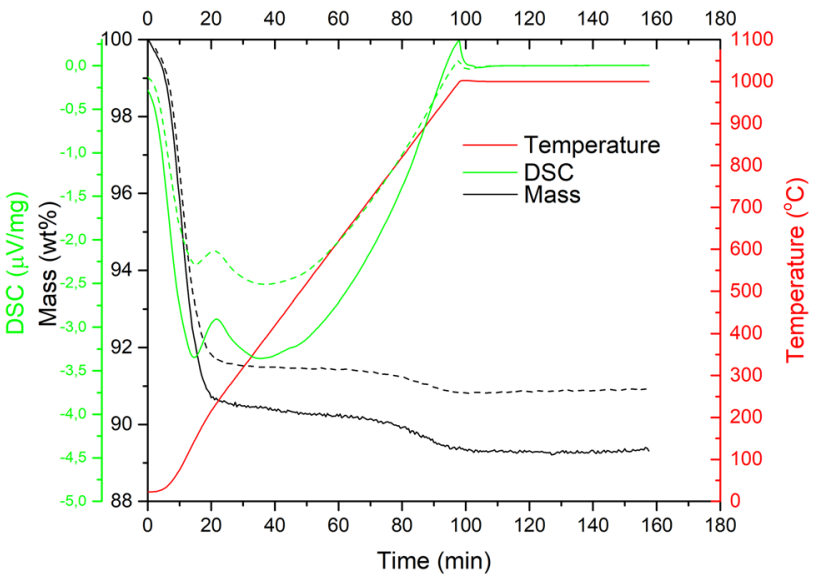

Fig. 5 Effect of desilication on the thermal stability of zeolite. HZSM5 (line) and Ds-HZSM5 (dashed line)

Thermal stability as assessed by TG/DSC (Fig. 5) is not affected by the alkaline treatment. This is can be seen by the similarity in mass and DSC curves upon heating in oxidative atmosphere. The observed differences in the actual mass loss of the two samples are due to physisorbed water, upon exposure to the atmosphere prior to measurement. The hydrothermal stability of the zeolite is of great importance when considering regeneration of the coked catalysts.

\subsection{Catalytic Pyrolysis}

\subsubsection{Product Yields and Composition}

As expected, the organic liquid yield is reduced by the use of catalysts (Fig. 6). The desilication and metal modification did not affect the water yield indicating that none of the treatments (desilication, metal incorporation) affect the dehydration reaction rates. In fact, decarbonylation and decarboxylation rates are enhanced by zeolite desilication as also seen by the total carbon oxides yields (Fig. 7). Interestingly, the incorporation of $\mathrm{Co}$ on the zeolite matrix results in increased $\mathrm{CO}_{2}$ production both for the untreated and the desilicated zeolite. This could partially be attributed to the $\mathrm{Co}_{3} \mathrm{O}_{4}$ reduction; however, metal modified catalysts exhibit higher Lewis acidity which favors the decarboxylation [41] and therefore increased $\mathrm{CO}_{2}$ production could also
Table 3 Acidity of prepared catalysts determined by pyridine adsorption-FTIR

\begin{tabular}{|c|c|c|c|c|c|c|c|}
\hline & \multirow[t]{2}{*}{$\mathrm{C}_{\mathrm{B}}(\mu \mathrm{mol} / \mathrm{g})$} & \multicolumn{4}{|c|}{ Brønsted sites } & \multirow[t]{2}{*}{$\mathrm{C}_{\mathrm{L}}(\mu \mathrm{mol} / \mathrm{g})$} & \multirow{2}{*}{$\begin{array}{l}\text { Total acid- } \\
\text { ity }(\mu \mathrm{mol} / \mathrm{g})\end{array}$} \\
\hline & & $\%$ Strong & $\%$ Medium & \%Weak & $\%$ Very weak & & \\
\hline HZSM5 & 421.98 & 75.9 & 13.6 & 6.15 & 4.36 & 83.77 & 505.75 \\
\hline Ds-HZSM5 & 311.21 & 75.84 & 7.43 & 12.54 & 5.08 & 94.7 & 405.91 \\
\hline Co/HZSM5 & 255.83 & 67.64 & 15.63 & 9.6 & 7.14 & 247.58 & 503.11 \\
\hline Co/Ds-HZSM5 & 121.18 & 57.5 & 16.96 & 14.29 & 11.16 & 452.76 & 573.94 \\
\hline
\end{tabular}




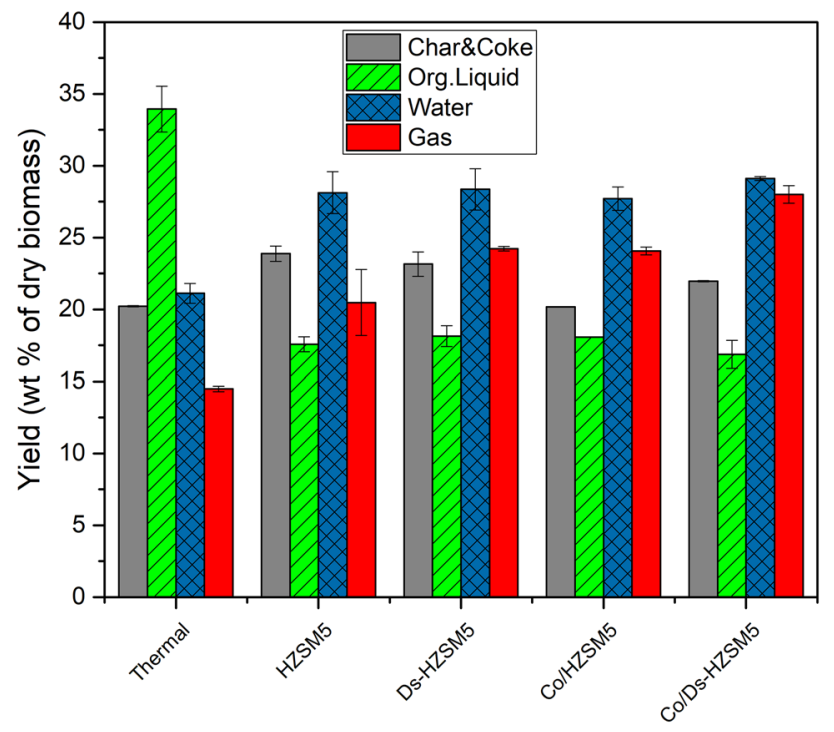

Fig. 6 Product distribution of catalytic pyrolysis of oak using different catalysts
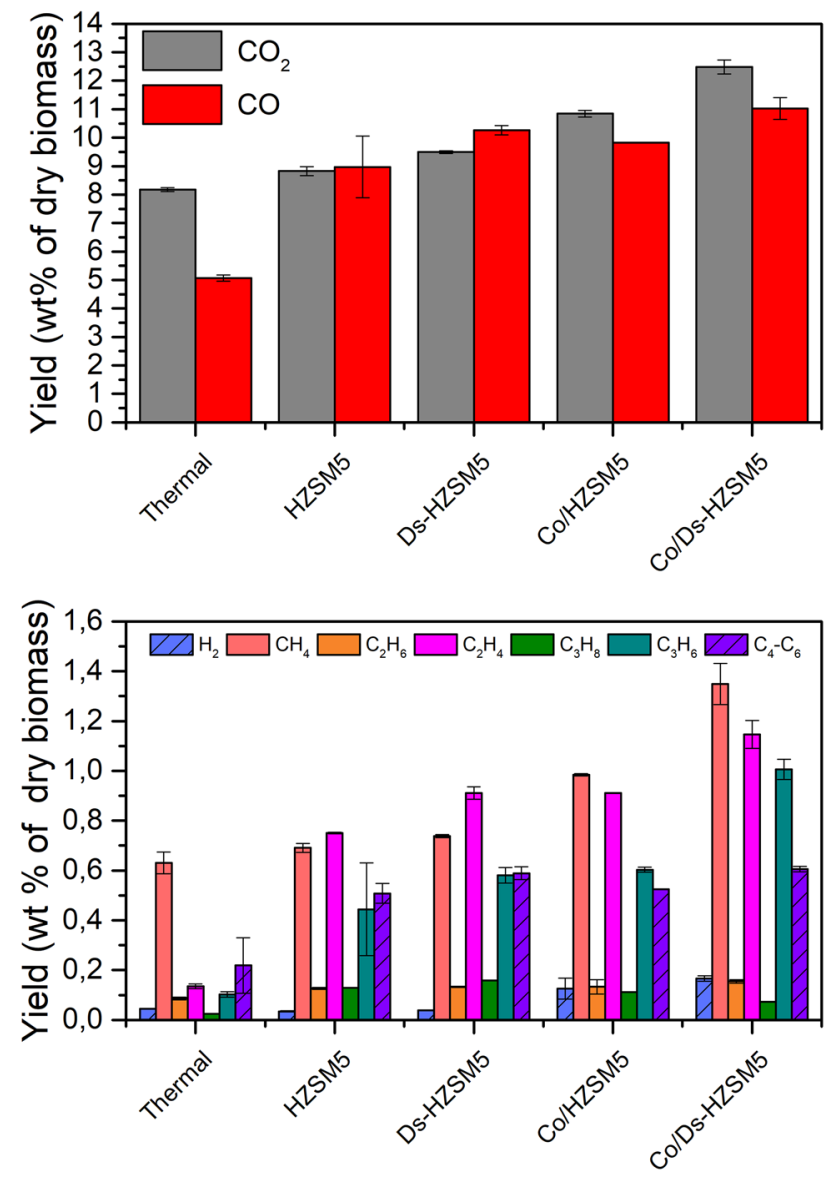

Fig. 7 Gas yields and composition of catalytic pyrolysis of oak

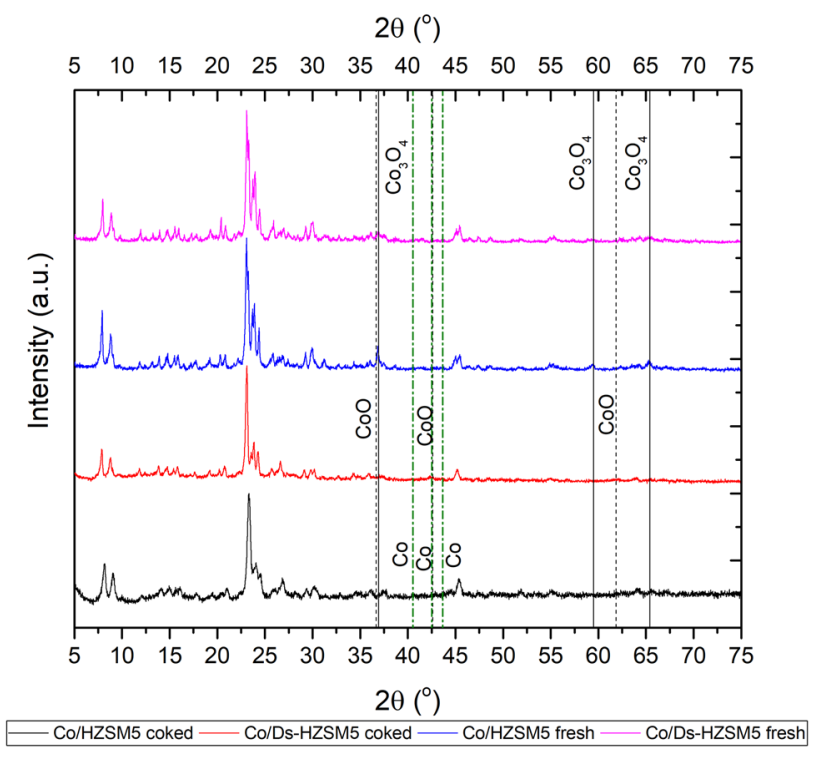

Fig. 8 XRD patters of fresh and spent cobalt modified HZSM5 catalysts

be associated with the altered acidic character of the metal modified zeolites. Examination of the XRD patterns of the coked zeolites and fresh Co containing zeolites do not show clear results on the state of Co (Fig. 8). The characteristic peaks of $\mathrm{Co}_{3} \mathrm{O}_{4}$ at $\left(2 \theta=36.9^{\circ}, 65.4^{\circ}\right.$ and $\left.59.5^{\circ}\right)$ are not present in the coked catalysts suggesting that partial or complete reduction has taken place. Reduction to metallic Co has been reported in previous studies [20]. It has also been found that the $\mathrm{Co}^{2+}$ cations in ZSM-5 cannot be altered in oxidation states upon oxygen and hydrogen treatment below $450{ }^{\circ} \mathrm{C}$ [42] and thus, given the relatively low temperature and short time on stream, cobalt ions inside the zeolite framework are difficult to be altered. In this case the framework of zeolites can function as a huge ligand to coordinate and stabilize its cations, preventing the latter from oxidation or reduction [29, 42].

The effect of Co incorporation on liquid composition can also be seen in Table 4 and in Fig. 9 that depicts the van Krevelen diagram of the resulted organic liquids on dry basis. The straight lines in Fig. 9 represent the different pathways of oxygen rejection. As shown, oxygen rejection as carbon oxides are the prevailing mechanisms. The deoxygenation activity of the catalysts tested decreases with the following order: Co/Ds-HZSM5 > Ds-HZSM5 > CoHZSM5 > HZSM5 achieving 22.58, 20.63, 12.11 and $10.83 \%$ reduction in $\mathrm{O}$ content compared to the thermal run (39.8 wt\% O) respectively. As shown, the increase in mesoporosity results in higher catalyst effectiveness towards deoxygenation. The $\mathrm{O}$ rejection in form of carbon oxides is preferred because of $\mathrm{H}$ preservation in the liquid products. This can be expressed in terms of the effective hydrogen 
Table 4 Average $\mathrm{CHO}$ composition (dry basis) of liquid derived from catalytic pyrolysis using different catalysts

\begin{tabular}{llll}
\hline & $\mathrm{C}(\mathrm{wt} \% \mathrm{db})$ & $\mathrm{H}(\mathrm{wt} \% \mathrm{db})$ & $\mathrm{O}(\mathrm{wt} \% \mathrm{db})$ \\
\hline Thermal (non-catalytic) & 54.04 & 6.17 & 39.79 \\
HZSM5 & 57.39 & 7.13 & 35.48 \\
Ds-HZSM5 & 58.81 & 7.04 & 31.58 \\
Co/HZSM5 & 57.76 & 7.27 & 34.97 \\
Co/Ds-HZSM5 & 61.63 & 7.56 & 30.80 \\
\hline
\end{tabular}

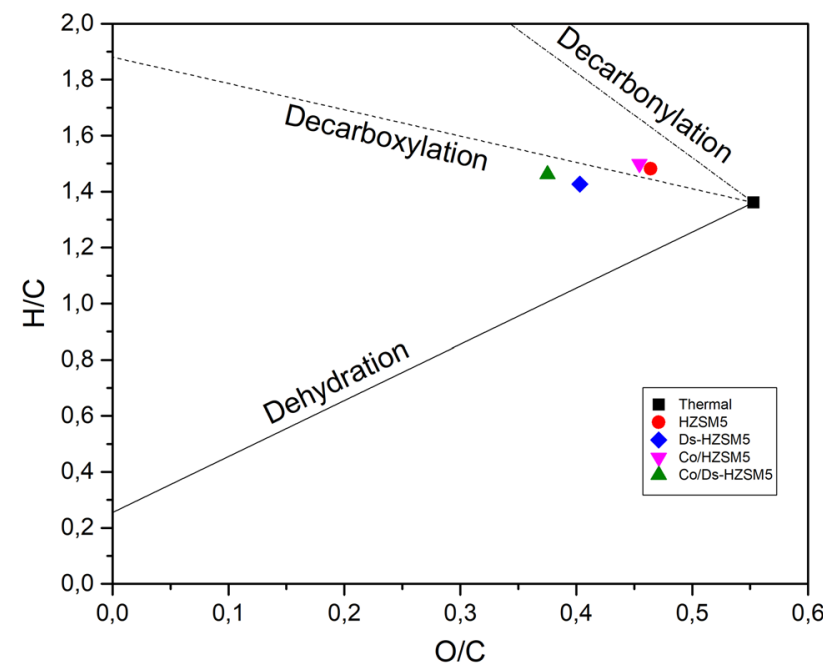

Fig. 9 Van Krevelen diagram of the organic liquids produced (dry basis) during catalytic pyrolysis using different catalysts

index (E.H.I.) which is defined as the net hydrogen to carbon ration after debiting the hydrogen content of the feed for complete removal of the heteroatoms present [43]. The calculated EHI values for HZSM5 Ds-HZSM5, Co/HZSM5 and Co-Ds/HZSM5 are $0.54,0.62,0.59$ and 0.71 respectively (EHI of the thermal run equalled to 0.25). The above results indicate that both Co modification and desilication promote the $\mathrm{O}$ rejection from the liquids in the form of carbon oxides.

$\mathrm{H}_{2}$ production is promoted using catalysts with Co modified catalysts resulting in a three and fourfold increase in the $\mathrm{H}_{2}$ content compared to parent and desilicated zeolites respectively. This indicates that dehydrogenation is favored (Fig. 7; Table 5). The desilicated catalysts showed higher selectivity to lighter olefins (ethylene and propylene) compared to non-desilicated counterparts. This could also be attributed to the faster diffusion for the desilicated materials due to the shorter path through the microporous channels and also to lower Brønsted acidity limiting in that way the aromatization reactions of the produced olefins. The faster diffusion of olefins from the micropore structure has also been identified as the reason for increased olefins selectivity during conversion of linear hydrocarbons (n-heptane) over hierarchical zeolites [44]. The introduction of Co seems to further promote olefins production due to low Brønsted acidity with the olefins production achieving an $80 \%$ (mass basis) increase compared to HZSM5.

GC/MS analysis of the organic liquid can also shed light of the underlying conversion mechanisms. As shown in Fig. 10 the aromatic hydrocarbon content increases with the increased mesoporosity. Cobalt modification and desilication results in reduction of aldehydes and ketones, which are considered as problematic compounds with regards to oil stability. The transformation of ketones involves direct decarbonylation in the first step with subsequent olefins oligomerization and aromatization. Carboxylic acids have been reduced by the use of all the catalysts without significant effects of metal incorporation and desilication.

The development of mesoporosity not only helps for faster diffusion from and to the micropores but also allows for the interaction of bigger aromatic molecules in the mesopore cavities and conversion to polyaromatic hydrocarbons (PAHs) in the presence of surface acid sites in the mesopores. This could explain the increased PAHs formation. However, Co modification (mainly deposited in the mesopores) seems to reduce these interactions. The increased PAHs yields along with increased olefins production indicates that the main source of aromatics is from lignin derivatives rather than Diels-Alder reactions of produced olefins. This finding indicates that controlled mesoporosity is necessary since increased mesopores would result in formation of heavier PAHs reducing the quality of the derived liquids.
Table 5 Gaseous hydrocarbons and carbon oxides selectivity

\begin{tabular}{|c|c|c|c|c|c|c|c|c|}
\hline & \multirow{2}{*}{$\frac{\mathrm{CO}}{\mathrm{CO}+\mathrm{CO}_{2}}$} & \multicolumn{6}{|c|}{ Hydrocarbon selectivity } & \multirow{2}{*}{$\begin{array}{l}\text { Total gaseous hydro- } \\
\text { carbons (wt \% of dry } \\
\text { biomass) }\end{array}$} \\
\hline & & $\mathrm{C}_{1}(\%)$ & $\mathrm{C}_{2}(\%)$ & $\mathrm{C}_{2}^{=}(\%)$ & $\mathrm{C}_{3}$ & $\mathrm{C}_{3}^{=}(\%)$ & $\mathrm{C}_{4}^{+}(\%)$ & \\
\hline Thermal & 0.49 & 73.12 & 5.34 & 10.39 & 1.02 & 4.50 & 5.63 & 1.20 \\
\hline HZSM5 & 0.61 & 43.51 & 4.24 & 31.52 & 2.95 & 10.66 & 7.11 & 2.65 \\
\hline Ds-HZSM5 & 0.63 & 40.39 & 3.90 & 33.25 & 3.16 & 12.13 & 7.17 & 3.11 \\
\hline Co/HZSM5 & 0.59 & 48.03 & 3.47 & 29.62 & 1.97 & 11.21 & 5.69 & 3.27 \\
\hline Co/Ds-HZSM5 & 0.58 & 49.24 & 3.01 & 27.89 & 0.97 & 13.98 & 4.91 & 4.33 \\
\hline
\end{tabular}



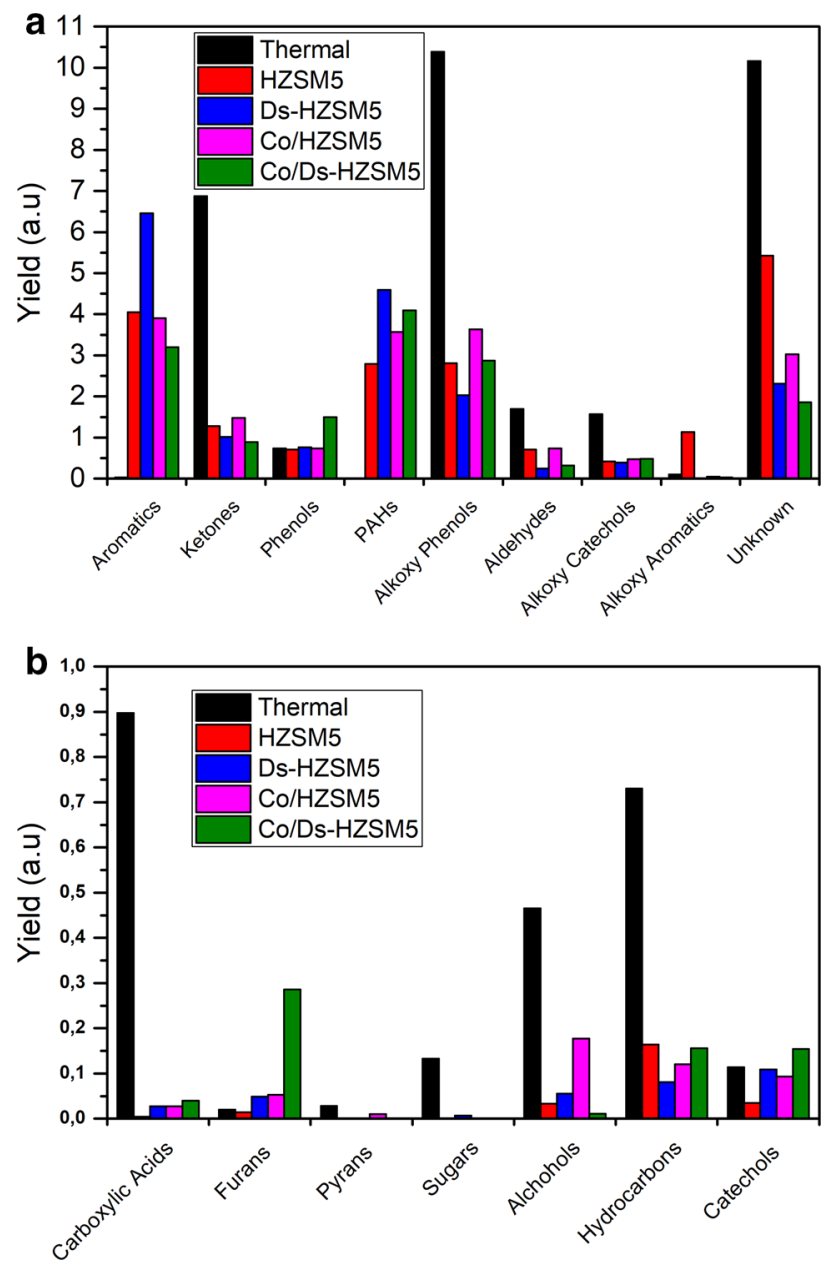

Fig. 10 Major (a) and minor (b) compounds in organic liquids obtained from catalytic pyrolysis of oak over HZSM5 catalysts

The milder acidic function of the Brønsted sites in the zeolite along with the increased Lewis acidity due to cobalt incorporation and mesoporous nature of the Co/Ds-HZSM5 promote the formation of phenols. Similar, results have been reported elsewhere [20].

As shown in Fig. 10, the conversion of alkoxy-phenols (main lignin derivatives) seem to be enhanced by the increased mesoporosity due to their bulk size at relatively increased Brønsted acidities. Reduction of Brønsted acidity and occupation of mesopores by Co reduce this effect. Co modification and desilication favor also furans formation due to minimization of secondary transformations [45].

\subsubsection{Coking Characteristics}

Carbon deposition on the catalysts after pyrolysis test (Fig. 11) shows that the coking tendency is reduced for the desilicated catalysts due to less diffusion limitations within or from the porous network. The coking tendency of the

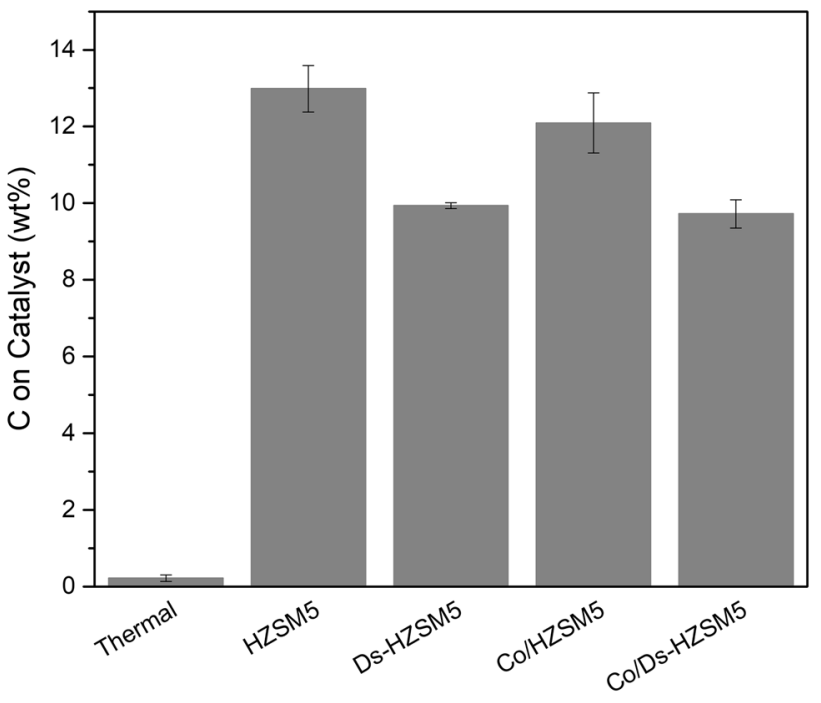

Fig. 11 Carbon deposition on the catalysts

investigated catalysts increases with the following order: $\mathrm{Co} /$ Ds-HZSM5 < Ds-HZSM5 < Co/HZSM5 < HZSM5.

Figure 12 shows the diffraction patterns of fresh and coked zeolites. Alternations can be seen in the $2 \theta$ region of $23^{\circ}-25^{\circ}$ both for HZSM5 and Ds-HZSM5. The fresh HZSM5 (Fig. 12(top)) exhibits a doublet at $2 \theta=23.08^{\circ}$ and $2 \theta=23.26^{\circ}$ which is also present at the coked HZSM5 pattern (at $2 \theta=23.36^{\circ}$ and $\left.23.4^{\circ}\right)$. However, the doublet of the fresh desilicated counterpart (Ds-HZSM5, Fig. 12 (bottom)) which is observed at $2 \theta=23.1^{\circ}$ and $2 \theta=23.28^{\circ}$, appears after coking as a single peak at $2 \theta=23.34^{\circ}$. Similar observation reported by Alvarez et al. [46]. when coking ZSM5 with $\mathrm{C}_{4}$ hydrocarbons. Differences in diffraction patterns are strongly related to the location of coke. It has been reported that the preservation of the doublet at $2 \theta=\sim 23^{\circ}$ is because of the coke deposition on the outer surface of the catalyst, while the absence of the doublet and collapse to one peak corresponds to cell distortion due to coke deposition within the pores [47]. The diffraction peaks are slightly shifted to higher angles probably because of higher internal stresses in the material due to coke presence.

Hence, the small pore size of the parent HZSM5 resulted in steric hindrances and therefore more deposition of coke on the outer surface, while easier access to the pore network in the Ds-HZSM5 resulted in coke deposition within the pore structure indicating that the volume of the catalysts is utilized more effectively.

GC-MS analysis of the soft $\left(\mathrm{CH}_{2} \mathrm{Cl}_{2}\right.$ soluble $)$ coke could also provide some insights about the coking mechanisms and coke precursors in the different catalysts. As shown in Fig. 13, the main compounds responsible for coke formation inside the pores of the microporous HZSM5 are esters. Esterification reactions take place at strong Brønsted sites 

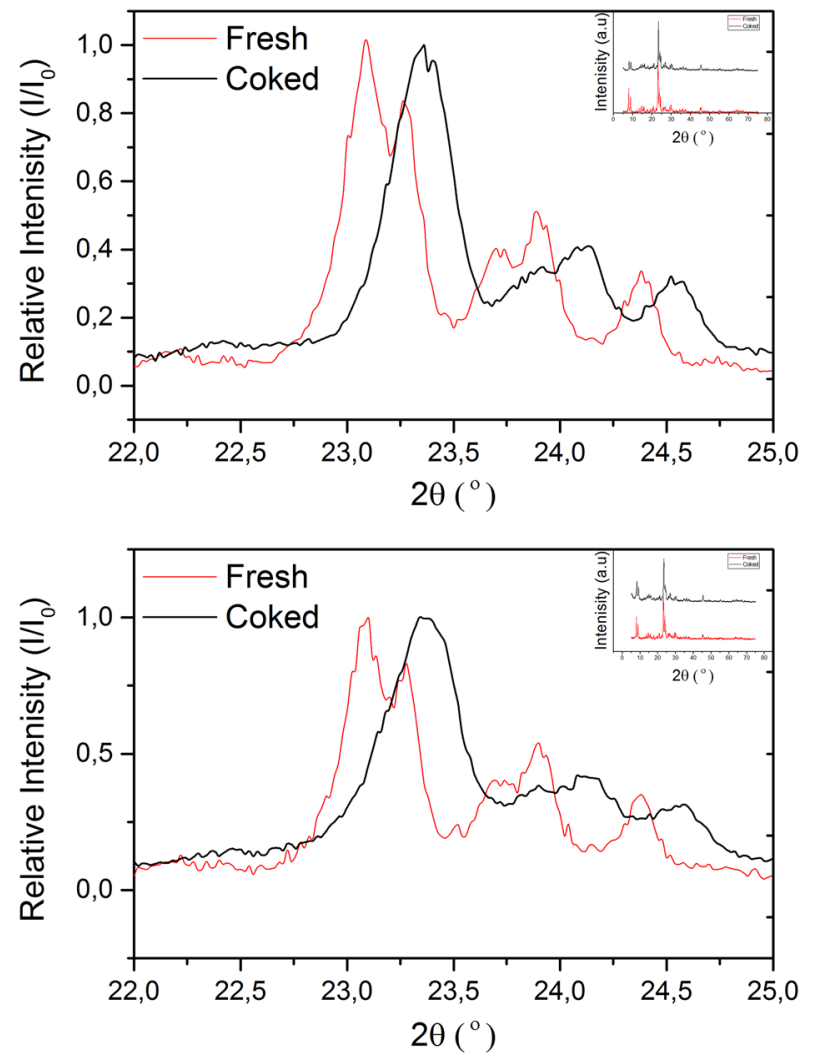

Fig. 12 Comparison of diffraction patterns of fresh and coked HZSM5 (top) and Ds-HZSM5 (bottom)

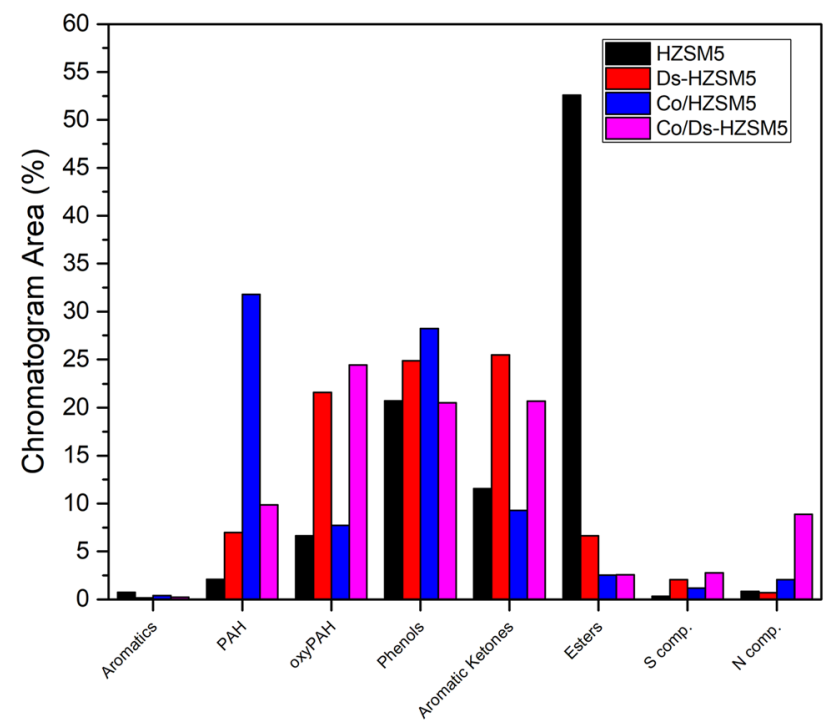

Fig. 13 GC-MS composition of $\mathrm{CH}_{2} \mathrm{Cl}_{2}$ soluble coke

[48] and given their availability in the parent HZSM5, they constitute the major fraction of the in pore coke precursors.

The aromatics content in the $\mathrm{CH}_{2} \mathrm{Cl}_{2}$ soluble coke is rather low for all the catalysts however the PAHs content increases with the instruction of mesoporosity. The main source of coke precursor in the hierarchical zeolites comes from bulky lignin derived molecules such as oxygenatedPAHs and aromatic ketones. Their high concentration in the coke comes from the easier accessibility to the pores [48] and results in their partial or complete deoxygenation.

\section{Conclusions}

The development of advanced catalytic materials could contribute to a more efficient catalytic pyrolysis process. In this work, the mesoporosity development by desilication of HZSM5 composite catalyst and metal incorporation of Co during catalytic pyrolysis of biomass was investigated. Characterization of the catalytic materials showed that desilication resulted in increased mesopores formation and slightly reduced Brønsted acidity while the incorporation of Co (mainly in the mesopores) resulted in increased Lewis acidity of the catalysts. The desilicated and cobalt modified showed to be 2.2 times more active towards deoxygenation reactions of the pyrolysis vapors while at the same time the carbon deposition was decreased by $\sim 25 \%$ compared to conventional microporous HZSM5 zeolite. XRD and GC/MS analyses of the coked catalysts verify the more efficient use of the desilicated catalysts. Most of the coke precursors in the catalysts are of oxy-aromatic and oxy-phenolic nature indicating the higher accessibility of bulky lignin derived molecules to the pores of the hierarchical catalysts. Concluding, tailoring the pore size together with metal modification is a promising route in catalytic biomass pyrolysis however the optimum operating conditions have to be determined under relevant industrial conditions.

Acknowledgements The authors would like to acknowledge BRISK for supporting this work.

\section{Compliance with Ethical Standards}

Conflict of interest The authors declare that they have no conflict of interest.

Open Access This article is distributed under the terms of the Creative Commons Attribution 4.0 International License (http://creativeco mmons.org/licenses/by/4.0/), which permits unrestricted use, distribution, and reproduction in any medium, provided you give appropriate credit to the original author(s) and the source, provide a link to the Creative Commons license, and indicate if changes were made. 


\section{References}

1. McKendry P (2002) Energy production from biomass (part 2): conversion technologies. Bioresour Technol 83:47-54. https://doi. org/10.1016/S0960-8524(01)00119-5

2. Iliopoulou EF, Triantafyllidis KS, Lappas AA (2018) Overview of catalytic upgrading of biomass pyrolysis vapors toward the production of fuels and high-value chemicals. Wiley Interdiscip Rev Energy Environ 8:e322. https://doi.org/10.1002/wene.322

3. Dahlquist E (2013) Technologies for converting biomass to useful energy. CRC Press, Boca Raton

4. Bridgwater AV (1999) Principles and practice of biomass fast pyrolysis processes for liquids. J Anal Appl Pyrolysis 51:3-22. https://doi.org/10.1016/S0165-2370(99)00005-4

5. Yarulina I, Chowdhury AD, Meirer F et al (2018) Recent trends and fundamental insights in the methanol-to-hydrocarbons process. Nat Catal 1:398-411. https://doi.org/10.1038/s4192 9-018-0078-5

6. Losch P, Hoff T, Kolb J et al (2017) Mesoporous ZSM-5 zeolites in acid catalysis: top-down vs bottom-up approach. Catalysts 7:225. https://doi.org/10.3390/catal7080225

7. Groen JC, Abelló S, Villaescusa LA, Pérez-Ramírez J (2008) Mesoporous beta zeolite obtained by desilication. Microporous Mesoporous Mater 114:93-102. https://doi.org/10.1016/J.MICRO MESO.2007.12.025

8. Li K, Valla J, Garcia-Martinez J (2014) Realizing the commercial potential of hierarchical zeolites: new opportunities in catalytic cracking. ChemCatChem 6:46-66. https://doi.org/10.1002/ cctc. 201300345

9. Groen JC, Moulijn JA, Pérez-Ramírez J (2007) Alkaline posttreatment of MFI zeolites. From accelerated screening to scale-up. Ind Eng Chem Res 46:4193-4201. https://doi.org/10.1021/ie061146v

10. Tarach KA, Góra-Marek K, Martinez-Triguero J, Melián-Cabrera I (2017) Acidity and accessibility studies of desilicated ZSM-5 zeolites in terms of their effectiveness as catalysts in acid-catalyzed cracking processes. Catal Sci Technol 7:858-873. https:// doi.org/10.1039/c6cy02609e

11. Parlett CMA, Wilson K, Lee AF (2013) Hierarchical porous materials: catalytic applications. Chem Soc Rev 42:3876-3893. https ://doi.org/10.1039/C2CS35378D

12. Holm MS, Svelle S, Joensen F et al (2009) Assessing the acid properties of desilicated ZSM-5 by FTIR using CO and 2,4,6-trimethylpyridine (collidine) as molecular probes. Appl Catal A Gen 356:23-30. https://doi.org/10.1016/J.APCATA.2008.11.033

13. Peréz-Ramírez J, Verboekend D, Bonilla A, Abelló S (2009) Zeolite catalysts with tunable hierarchy factor by pore-growth moderators. Adv Funct Mater 19:3972-3979. https://doi.org/10.1002/ adfm. 200901394

14. Li J, Li X, Zhou G et al (2014) Catalytic fast pyrolysis of biomass with mesoporous ZSM-5 zeolites prepared by desilication with $\mathrm{NaOH}$ solutions. Appl Catal A Gen 470:115-122. https://doi. org/10.1016/J.APCATA.2013.10.040

15. Hoff TC, Gardner DW, Thilakaratne R et al (2017) Elucidating the effect of desilication on aluminum-rich ZSM-5 zeolite and its consequences on biomass catalytic fast pyrolysis. Appl Catal A Gen 529:68-78. https://doi.org/10.1016/j.apcata.2016.10.009

16. Hoff TC, Gardner DW, Thilakaratne R et al (2016) Tailoring ZSM-5 Zeolites for the fast pyrolysis of biomass to aromatic hydrocarbons. Chemsuschem 9:1473-1482. https://doi. org/10.1002/cssc. 201600186

17. French R, Czernik S (2010) Catalytic pyrolysis of biomass for biofuels production. Fuel Process Technol 91:25-32. https://doi. org/10.1016/J.FUPROC.2009.08.011

18. Vichaphund S, Aht-ong D, Sricharoenchaikul V, Atong D (2014) Catalytic upgrading pyrolysis vapors of Jatropha waste using metal promoted ZSM-5 catalysts: an analytical PY-GC/ MS. Renew Energy 65:70-77. https://doi.org/10.1016/j.renen e.2013.07.016

19. Iliopoulou EF, Stefanidis S, Kalogiannis K et al (2014) Pilotscale validation of Co-ZSM- 5 catalyst performance in the catalytic upgrading of biomass pyrolysis vapours. Green Chem 16:662674. https://doi.org/10.1039/c3gc41575a

20. Iliopoulou EF, Stefanidis SD, Kalogiannis KG et al (2012) Catalytic upgrading of biomass pyrolysis vapors using transition metal-modified ZSM-5 zeolite. Appl Catal B Environ 127:281290. https://doi.org/10.1016/j.apcatb.2012.08.030

21. Zheng Y, Wang F, Yang X et al (2017) Study on aromatics production via the catalytic pyrolysis vapor upgrading of biomass using metal-loaded modified H-ZSM-5. J Anal Appl Pyrolysis 126:169-179. https://doi.org/10.1016/J.JAAP.2017.06.011

22. Groen JC, Peffer LAA, Moulijn JA, Pérez-Ramírez J (2005) Role of intrinsic zeolite properties on mesopore formation by desilication of MFI structures. Stud Surf Sci Catal 156:401-408. https:// doi.org/10.1016/S0167-2991(05)80235-6

23. Triantafyllidis KS, Iliopoulou EF, Antonakou EV et al (2007) Hydrothermally stable mesoporous aluminosilicates (MSU-S) assembled from zeolite seeds as catalysts for biomass pyrolysis. Microporous Mesoporous Mater 99:132-139. https://doi. org/10.1016/j.micromeso.2006.09.019

24. Antonakou E, Lappas A, Nilsen MH et al (2006) Evaluation of various types of Al-MCM-41 materials as catalysts in biomass pyrolysis for the production of bio-fuels and chemicals. Fuel 85:2202-2212. https://doi.org/10.1016/J.FUEL.2006.03.021

25. Puértolas B, Veses A, Callén MS et al (2015) Porosity-acidity interplay in hierarchical ZSM-5 zeolites for pyrolysis oil valorization to aromatics. Chemsuschem 8:3283-3293. https://doi. org/10.1002/cssc. 201500685

26. Stefanidis S, Kalogiannis K, Iliopoulou EF et al (2013) Mesoporemodified mordenites as catalysts for catalytic pyrolysis of biomass and cracking of vacuum gasoil processes. Green Chem 15:16471658. https://doi.org/10.1039/c3gc40161h

27. Magnoux P, Roger P, Canaff C et al (1987) New technique for the characterization of carbonaceous compounds responsible for zeolite deactivation. Stud Surf Sci Catal 34:317-330. https://doi. org/10.1016/S0167-2991(09)60370-0

28. Gamliel DP, Cho HJ, Fan W, Valla JA (2016) On the effectiveness of tailored mesoporous MFI zeolites for biomass catalytic fast pyrolysis. Appl Catal A Gen 522:109-119. https://doi. org/10.1016/J.APCATA.2016.04.026

29. Jong S-J, Cheng S (1995) Reduction behavior and catalytic properties of cobalt containing ZSM-5 zeolites. Appl Catal A Gen 126:51-66. https://doi.org/10.1016/0926-860X(95)00016-X

30. Ayodele OB (2017) Influence of oxalate ligand functionalization on Co/ZSM-5 activity in Fischer Tropsch synthesis and hydrodeoxygenation of oleic acid into hydrocarbon fuels. Sci Rep 7:10008. https://doi.org/10.1038/s41598-017-09706-z

31. Lønstad Bleken F, Barbera K, Bonino F et al (2013) Catalyst deactivation by coke formation in microporous and desilicated zeolite H-ZSM-5 during the conversion of methanol to hydrocarbons. J Catal 307:62-73. https://doi.org/10.1016/j.jcat.2013.07.004

32. Sadowska K, Wach A, Olejniczak Z et al (2013) Hierarchic zeolites: zeolite ZSM-5 desilicated with $\mathrm{NaOH}$ and $\mathrm{NaOH} /$ tetrabutylamine hydroxide. Microporous Mesoporous Mater 167:82-88. https://doi.org/10.1016/J.MICROMESO.2012.03.045

33. Thibault-Starzyk F, Stan I, Abelló S et al (2009) Quantification of enhanced acid site accessibility in hierarchical zeolites- the accessibility index. J Catal 264:11-14. https://doi.org/10.1016/J. JCAT.2009.03.006

34. Groen JC, Peffer LAA, Moulijn JA, Pérez-Ramírez J (2005) Mechanism of hierarchical porosity development in MFI zeolites by desilication: the role of aluminium as a pore-directing 
agent. Chem-A Eur J 11:4983-4994. https://doi.org/10.1002/ chem.200500045

35. Bortnovsky O, Sobalík Z, Wichterlová B, Bastl Z (2002) Structure of Al-Lewis Site in beta zeolite active in the MeerweinPonndorf-Verley reduction of ketone to alcohol. J Catal 210:171182. https://doi.org/10.1006/jcat.2002.3661

36. Xing J, Song L, Zhang C et al (2015) Effect of acidity and porosity of alkali-treated ZSM-5 zeolite on eugenol hydrodeoxygenation. Catal Today 258:90-95. https://doi.org/10.1016/J.CATTO D.2015.04.014

37. Lee JY, Park SM, Saha SK et al (2011) Liquid-phase degradation of polyethylene (PE) over MFI zeolites with mesopores: effects of the structure of PE and the characteristics of mesopores. Appl Catal B Environ 108-109:61-71. https://doi.org/10.1016/J. APCATB.2011.08.009

38. Rao VUS, Gormley RJ, Schehl RR, Rhee KH, Chi RDH, Pantages G (1984) Metal-zeolite catalysts for the conversion of synthesis gas to selected hydrocarbon products. In: Herman RG (ed) Conversions of synthesis gas and alcohols to chemicals. Springer, US, pp 151-165

39. Mhamdi M, Khaddar-Zine S, Ghorbel A (2004) Influence of the cobalt salt precursor on the catalytic properties of H-ZSM-5 modified with cobalt by solid-state ion exchange. Stud Surf Sci Catal 154:2668-2673. https://doi.org/10.1016/S0167-2991(04)80539-1

40. Pierella LB, Saux C, Caglieri SC et al (2008) Catalytic activity and magnetic properties of Co-ZSM-5 zeolites prepared by different methods. Appl Catal A Gen 347:55-61. https://doi. org/10.1016/j.apcata.2008.05.033

41. Wang D, Hakim SH, Alonso DM, Dumesic JA (2013) A highly selective route to linear alpha olefins from biomass-derived lactones and unsaturated acids. Chem Commun 49:29. https://doi. org $/ 10.1039 / \mathrm{c} 3 \mathrm{cc} 43587 \mathrm{c}$

42. Sun T, Trudeau ML, Ying JY (1996) The nature of cobalt species in Co-ZSM-5 NO emission control catalysts. J Phys Chem 100:13662-13666. https://doi.org/10.1021/jp953678n
43. Chen NY, Walsh DE, Koenig LR (1988) Fluidized-bed upgrading of wood pyrolysis liquids and related compounds. In: Soltes J, Milne T (eds) Pyrolysis oils from biomass producing, analyzing, and upgrading. ACS Publications, Washington DC, pp 277-289

44. Zhang X, Cheng D, Chen F, Zhan X (2017) n-Heptane catalytic cracking on hierarchical ZSM-5 zeolite: the effect of mesopores. Chem Eng Sci 168:352-359. https://doi.org/10.1016/j. ces.2017.05.012

45. Kantarelis E, Yang W, Blasiak W (2014) Effect of zeolite to binder ratio on product yields and composition during catalytic steam pyrolysis of biomass over transition metal modified HZSM5. Fuel 122:119-125. https://doi.org/10.1016/j.fuel.2013.12.054

46. Alvarez AG, Viturro H, Bonetto RD (1992) Structural changes on deactivation of ZSM-5. A study by X-ray powder diffraction. Mater Chem Phys 32:135-140. https://doi.org/10.1016/02540584(92)90269-E

47. Uguina MA, Serrano DP, Van Grieken R, Vènes S (1993) Adsorption, acid and catalytic changes induced in ZSM- 5 by coking with different hydrocarbons. Appl Catal A Gen 99:97-113. https://doi. org/10.1016/0926-860X(93)80093-6

48. Zhang Huai-Bin, Zhang Kui, Yuan Zhong-Yong, Zhao Wei, Li H-X (1997) Surface acidity of zeolite ZSM-5 and its catalytis properties in esterification of acetic acid with alcohols. J Nat Gas Chem 6:228-236

Publisher's Note Springer Nature remains neutral with regard to jurisdictional claims in published maps and institutional affiliations. 